\title{
Effect of the knee-chest position on cerebral blood flow in patients undergoing lumbar spinal surgery
}

\author{
J-F PITTET, * A RAMADAN, $\dagger$ D R MOREL, * A FORSTER* \\ From the Departments of Anaesthesiology* and Neurosurgery, $\dagger$ University Hospital of Geneva, Switzerland
}

SUMMARY The cerebral haemodynamic effect of the knee-chest position was evaluated in 15 anaesthetised patients undergoing elective lumbar disc surgery and divided into a control group $(n=8)$ where cerebral blood flow $(C B F)$ was measured twice in the supine position and an experimental group $(n=7)$ where the first $C B F$ was measured in the supine position and the second in the knee-chest position. CBF was measured by a modified intravenous ${ }^{133}$ xenon washout technique. Mean global CBF did not change in control group (56.1, SD 9.2 versus 52.8, SD 10.8 units) and was not significantly modified by the knee-chest posture, 51.8, SD $8 \cdot 8$ units versus 53.9, SD $7 \cdot 4$ units in the supine position. The results indicate that mean global CBF in the knee-chest position is not different from $\mathrm{CBF}$ in the supine position in healthy patients.

The knee-chest position for lumbar intervertebral disc surgery has many advantages: excellent exposure of interlaminar spaces, avoidance of epidural venous engorgement with decreased blood loss, easy administration of intermittent positive pressure ventilation and decreased risk of injury to major prevertebral vessels and organs even in obese patients. ${ }^{1-4}$ However, undesirable effects of the knee-chest position have been reported, such as persistent postoperative pain in the hip and the quadriceps area, deep vein thrombosis, ${ }^{6}$ bilateral calf-muscle ischaemia with rhabdomyolysis and acute renal failure ${ }^{7}$ due to the prolonged flexion of the lower limbs and systemic hypotension when the legs are straightened at the end of surgery. ${ }^{6}$

The knee-chest position is not a physiological position. It could theoretically produce a significant decrease in CBF, especially in old arteriosclerotic patients, ${ }^{8}$ since the head is slightly downwards (fig 1 ). Furthermore in our practice, we have occasionally observed oedema and venous stasis of the face at the end of surgery. If similar stasis occurred in the cerebral veins, it could also increase intracranial pressure and possibly decrease CBF.

The present study was designed to compare the effect of the knee-chest with the supine position on $\mathrm{CBF}$ in patients undergoing elective lumbar disc surgery.

Correspondence to: Jean-Francois Pittet, Department of Anaesthesiology, University Hospital of Geneva, 1211 Geneva 4, Switzerland.

Received 29 November 1988 and in revised form 15 April 1989. Accepted 7 May 1989

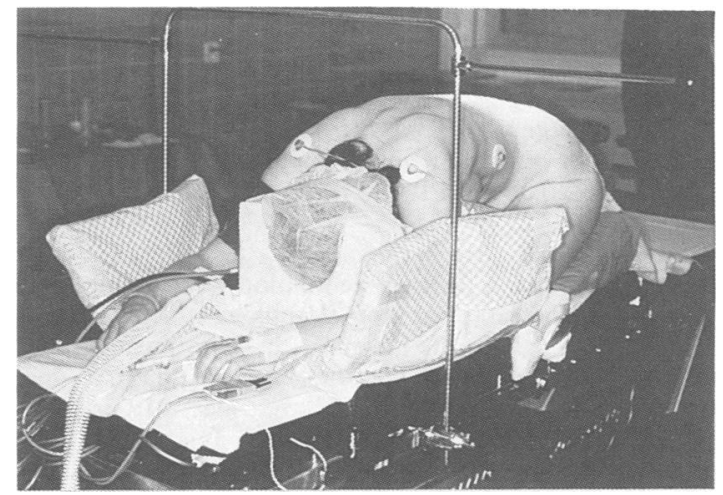

Fig 1 The knee-chest position, described by Lipton in 1950, and used in this study.

Methods

\section{Patients}

After informed consent and institutional approval, sixteen patients scheduled for elective lumbar intervertebral disc surgery participated in the study. The patients were randomly divided into a control $(n=8)$ and an experimental group $(n=7)$. Patients more than 62 years old, or with cardiovascular, pulmonary, or neurological diseases, or under medication other than minor analgesics, were excluded from the study. Moreover, the patients enrolled in the study were immediately excluded from the investigation if they had cardiac arrhythmias or a decrease of more than $30 \%$ of mean systemic arterial pressure (MAP) after induction of anaesthesia despite a rapid infusion of $500 \mathrm{ml}$ of crystalloids.

\section{Procedure}

The effects of knee-chest position on cerebral haemo- 
dynamics were measured after induction of anaesthesia and before the beginning of surgery. The patients were premedicated with morphine $0.1 \mathrm{mg} / \mathrm{kg}$ im and atropine $0.5 \mathrm{mg}$ im 45 minutes prior to anaesthesia. Anaesthesia was induced with thiopentone $5 \mathrm{mg} / \mathrm{kg}$ iv, fentanyl $2 \mu \mathrm{g} / \mathrm{kg}$ iv, pancuronium $0.1 \mathrm{mg} / \mathrm{kg}$ iv and was maintained after endotracheal intubation and controlled mechanical ventilation (respiratory frequency $10 / \mathrm{min}$ ) with $60 \% \mathrm{~N}_{2} \mathrm{O}, 40 \% \mathrm{O}_{2}$ and an end-tidal concentration of isoflurane of $0.5 \%$ precisely adjusted using a multiple gas analyser (Capnomac, Datex Instrumentarium Corporation, Helsinki). The study was started at least 30 minutes after the beginning of anaesthesia when the patients had attained stable systemic haemodynamics with a MAP within $\pm 30 \%$ of preoperative values and with a stable sinus heart rate.

Each patient of both groups was investigated during two periods of 11 minutes separated by an interval of 20 minutes. In the eight patients of the control group, $\mathrm{CBF}$ was measured twice in the supine position. In the seven patients of the experimental group, CBF was measured first in the supine position and second 15 minutes after having positioned the patient in the knee-chest position (islamic praying position) described by Lipton.' The operating table was maintained strictly horizontal during the whole experimental procedure. The head of the patient was kept in a neutral position to avoid extreme flexion or extension of the neck. All reported respiratory and systemic haemodynamic data were the mean of three measurements recorded one, five, and 10 minutes after the beginning of each CBF measurement.

The percentage of inspired $\mathrm{O}_{2}\left(\mathrm{~F}_{1} \mathrm{O}_{2}\right)$ was maintained at 0.4 . The inspiratory minute volume was adjusted (by changing tidal volume) to obtain a $\mathrm{P}_{\mathrm{a}} \mathrm{CO}_{2}$ between $35-45 \mathrm{~mm} \mathrm{Hg}$.

\section{Measured Variables and Techniques}

Intermittent positive pressure ventilation was administered using a volumetric respirator (Ventilog 1, Drägerwerk, Lübeck) connected to the lumen of the endotracheal tube. End-tidal isoflurane, $\mathrm{CO}_{2} ; \mathrm{N}_{2} \mathrm{O}$, end-inspiratory and end-expiratory $\mathrm{O}_{2}$ concentrations were measured using a multiple gas analyser (Capnomac, Datex Instrumentarium Corporation, Helsinki).

Peak inspiratory airway pressure and plateau airway pressure were recorded from the airflow pressure gauge of the respirator. Static total respiratory compliance was calculated by dividing plateau airway pressure by inspiratory tidal volume.

MAP was measured from a radial arterial cannula and central venous pressure (CVP) from a $16 \mathrm{G}$ intravenous catheter introduced through the vena basilica into the right atrium. The catheters were connected to calibrated quartz pressure transducers (1290 A Hewlett-Packard) positioned at the midaxillary line. The position of the CVP catheter was carefully controlled by a chest radiograph and by monitoring the presence of $a$ and $v$ pressure waves of the right atrium during CVP measurement in the supine position. Similarly, any major displacement of the tip of CVP catheter during the movement from supine to knee-chest position was excluded by monitoring a and $\mathrm{v}$ pressure waves of the right atrium before injection of ${ }^{133}$ xenon in the knee-chest position.

Systemic arterial blood samples were drawn for the measurement of $\mathrm{P}_{2} \mathrm{O}_{2}, \mathrm{P}_{\mathrm{a}} \mathrm{CO}_{2}$ and $\mathrm{pH}$ with standard electrodes (ABL 330, Radiometer Copenhagen) one minute before and five minutes after each CBF measurement.

CBF was measured using a cerebrograph Novo 10A (Novo Diagnostic Systems, Copenhagen), after injection of 10 millicuries of ${ }^{133}$ xenon diluted in a saline solution into the right atrium at end-inspiration. Three hemispheric detection probes placed on either side of the head at precisely identical anatomical localisation were used. CBF was determined by the Risberg' version of the two-compartmental model first described by Obrist. ${ }^{10}$

Based on the cerebral clearance of ${ }^{133}$ xenon, the modified initial slope index (ISI) according to Risberg' representing the monoexponential slope of the early part of the ${ }^{133}$ xenon concentration curve between 0.5 and 1.5 minutes was calculated (mean of six detectors); this index reflects clearance from fast $(2 / 3)$ and slow (1/3) compartments and represents the mean cerebral blood flow.

\section{Statistical Analysis}

The data (mean, SD) during the four CBF determinations were compared respectively by paired (within same group) and unpaired (between groups) Student's $t$ tests, taking a value $<0.05$ as statistically significant.

\section{Results}

The patients' age and weight were similar in both groups: 38,6 years and $75,23 \mathrm{~kg}$ for the control group, 41,10 years and 74, $9 \mathrm{~kg}$ for the experimental group. Respiratory, systemic and cerebral haemodynamic variables are summarised in tables 1 and 2 . In order to obtain a $\mathrm{P}_{\mathrm{a}} \mathrm{CO}_{2}$ between $35-45 \mathrm{~mm} \mathrm{Hg}$ at a respiratory rate of $10 /$ minute, a tidal volume of $7.0,1.6 \mathrm{ml} / \mathrm{kg}$ in the supine position, and of $7 \cdot 6,1 \cdot 1 \mathrm{ml} / \mathrm{kg}$ in the kneechest position was necessary. $\mathrm{P}_{\mathrm{a}} \mathrm{O}_{2}$, peak airway pressure and plateau airway pressure values were similar in

Table 1 Respiratory variables, mean value, SD

\begin{tabular}{|c|c|c|c|c|}
\hline & \multicolumn{2}{|c|}{ Control group $(n=8)$} & \multicolumn{2}{|c|}{ Experimental group $(n=7)$} \\
\hline & $\begin{array}{l}\text { Ist measurement } \\
\text { Supine position }\end{array}$ & $\begin{array}{l}\text { 2nd measurement } \\
\text { Supine position }\end{array}$ & $\begin{array}{l}\text { Ist measurement } \\
\text { Supine position }\end{array}$ & $\begin{array}{l}\text { 2nd measurement } \\
\text { Knee-chest position }\end{array}$ \\
\hline 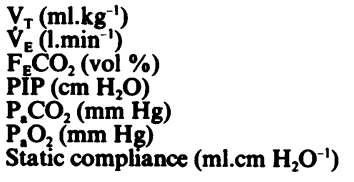 & $\begin{array}{rr}7 \cdot 0, & 1 \cdot 4 \\
5 \cdot 3, & 1 \cdot 1 \\
4 \cdot 6, & 0 \cdot 2 \\
20 \cdot 1, & 7 \cdot 4 \\
35 \cdot 3, & 2 \cdot 3 \\
142 \cdot 5,36 \cdot 8 \\
47 \cdot 0 ; 11 \cdot 5\end{array}$ & $\begin{array}{r}6 \cdot 9,1 \cdot 5 \\
5 \cdot 2,1 \cdot 3 \\
4 \cdot 5,0 \cdot 3 \\
20 \cdot 0,6 \cdot 5 \\
36,2 \cdot 3 \\
141 \cdot 2,36 \\
45 \cdot 4,10 \cdot 3\end{array}$ & $\begin{array}{rr}7 \cdot 0, & 1 \cdot 6 \\
5 \cdot 4, & 1 \cdot 3 \\
4 \cdot 8, & 0 \cdot 3 \\
23 \cdot 4, & 5 \cdot 8 \\
38 \cdot 3, & 4 \cdot 6 \\
138 \cdot 8,26 \cdot 3 \\
51 \cdot 5,13 \cdot 1\end{array}$ & $\begin{array}{rr}7 \cdot 6, & 1 \cdot 1 \\
6 \cdot 0, & 0 \cdot 9 \\
4 \cdot 5, & 0 \cdot 4 \\
20 \cdot 8, & 4 \cdot 5 \\
36 \cdot 8, & 3 \cdot 8 \\
150 \cdot 8, & 33 \cdot 8 \\
56 \cdot 4,12 \cdot 1\end{array}$ \\
\hline
\end{tabular}

$\mathrm{V}_{\mathrm{T}}$ : Tidal Volume; $\mathrm{V}_{\mathrm{E}}$ : Expiratory Minute Volume; $\mathrm{F}_{\mathrm{E}} \mathrm{CO}_{2}$ : End-tidal $\mathrm{CO}_{2}$ Fraction; PIP: Peak Inspiratory Airway Pressure. 
Table 2 Systemic and cerebral haemodynamic variables, mean value, SD

\begin{tabular}{|c|c|c|c|c|}
\hline & \multicolumn{2}{|c|}{ Control group $(n=8)$} & \multicolumn{2}{|c|}{ Experimental group $(n=7)$} \\
\hline & $\begin{array}{l}\text { Ist measurement } \\
\text { Supine position }\end{array}$ & $\begin{array}{l}\text { 2nd measurement } \\
\text { Supine position }\end{array}$ & $\begin{array}{l}\text { Ist measurement } \\
\text { Supine position }\end{array}$ & $\begin{array}{l}\text { 2nd measurement } \\
\text { Knee-chest position }\end{array}$ \\
\hline $\begin{array}{l}\text { MAP (mm Hg) } \\
\text { HR (beats.min }{ }^{-1} \text { ) } \\
\text { CVP (mm Hg) } \\
\text { ISI (units) }\end{array}$ & $\begin{array}{l}73,9 \\
75,13 \\
3 \cdot 5,1 \cdot 7 \\
56 \cdot 1,9 \cdot 2\end{array}$ & $\begin{array}{cl}70, & 7 \\
70, & 9 \\
4 \cdot 3, & 1 \cdot 3 \\
52 \cdot 8, & 10 \cdot 8\end{array}$ & $\begin{array}{r}73,4 \\
72,7 \\
4 \cdot 8,2 \cdot 9 \\
53 \cdot 9,7 \cdot 4\end{array}$ & $\begin{array}{c}74,7 \\
67,8 \\
3 \cdot 1,2 \cdot 9 \\
51 \cdot 8,8 \cdot 8\end{array}$ \\
\hline
\end{tabular}

MAP: Mean Arterial Pressure; HR: Heart Rate; CVP: Central Venous Pressure; ISI: Initial Slope Index representing the Mean Global CBF.

both groups of patients during the whole investigation. Static total respiratory compliance was not different in both groups of patients whatever the body position. No significant differences in any of the haemodynamic variables were detected between both groups of patients. Rectal temperature was maintained for all patients in a narrow range during the whole investigation (control group: $36.2,0.7^{\circ} \mathrm{C}$; experimental group: $35.9,0.8^{\circ} \mathrm{C}$ ). All patients were remarkably stable during the two sessions of the investigation; in particular, the determinants of CBF varied in each patient less than 5\%: $\mathrm{P}_{\mathrm{2}} \mathrm{CO}_{2}$ (range: $2 \cdot 0$ $2 \cdot 3 \%$ ), rectal temperature (range: $0 \cdot 7-1 \cdot 0 \%$ ), MAP (range: $3 \cdot 5-4 \cdot 0 \%$ ).

The comparison of both groups of patients during the baseline CBF measurements, indicates that no significant differences in baseline ISI were observed. Comparing cerebral haemodynamics within each group indicates ISI did not change in the control group $(56 \cdot 1,9 \cdot 2$ vs $52 \cdot 8,10 \cdot 8$ units $)$ and was not significantly

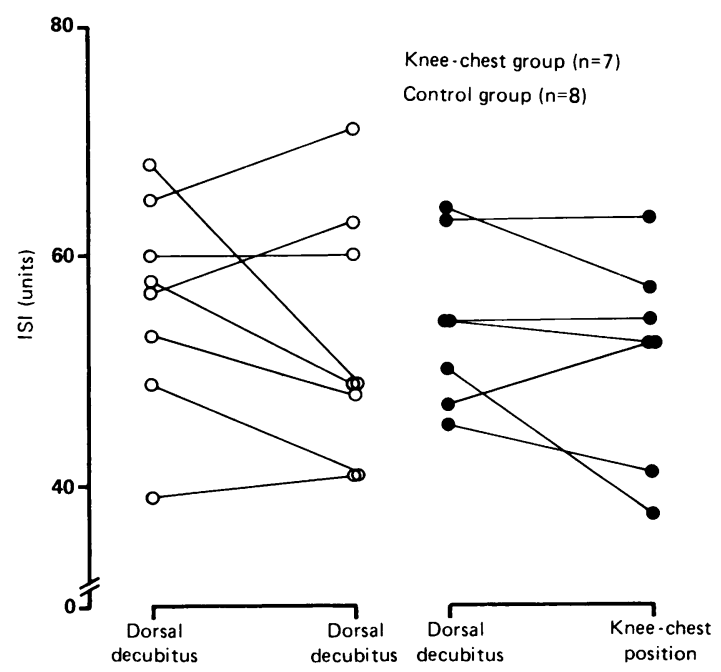

Fig 2 Individual modified initial slope values (ISI) during both CBF measurements. modified by the knee-chest posture $(53 \cdot 9,7 \cdot 4$ vs $51 \cdot 8$, 8.8 units) (fig 2).

\section{Discussion}

The present study demonstrates that global cerebral blood flow expressed as ISI is not significantly affected by the knee-chest position in non arteriosclerotic patients.

Although the classical main determinants of CBF $\left(\mathrm{P}_{\mathrm{a}} \mathrm{CO}_{2}\right.$, rectal temperature and MAP) were maintained for all patients in a narrow physiological range, we observed a relative high dispersion of ISI values during the first CBF measurement in the supine position in both groups of patients. This can be explained by the fact that at the low end-tidal concentration administered $(0.5 \%)$, isoflurane may produce different levels of anaesthesia, ${ }^{11}$ resulting in the patients with a light anaesthesia in a higher mean global CBF. This great variation in baseline CBF cannot be attributed to induction of anaesthesia and endotracheal intubation since patients with changes of more than $30 \%$ of MAP were excluded from the study, and MAP of all of the investigated patients remained during the whole investigation within the range of CBF autoregulation which is not influenced by isoflurane at the end-tidal concentration of $0.5 \% .^{1213}$ Finally, the time elapsed between the induction of anaesthesia and the beginning of the study was long enough (30 minutes) to exclude a residual haemodynamic effect of endotracheal intubation on CBF. ${ }^{14}$

Analysis of individual changes in ISI values between both CBF measurements reveals a great stability of mean global CBF whatever the position of the patient. Contrary to our expectations, the possible alteration of venous return from the head and the limbs ${ }^{8}$ and the change of the distribution of cerebral fluid pressure ${ }^{15}$ induced by the knee-chest posture did not produce in this study any modification of the global cerebral blood flow. Our results are in accordance with the previous study of Nelson ${ }^{16}$ who reported a surprisingly sustained increase in mean global CBF during anaesthesia and surgery in the sitting position, when 
compared with the supine position. As suggested by Nelson, ${ }^{16}$ these results as well as our data should probably be attributed to a specific form of CBF autoregulation accompanying the change in posture.

In conclusion, our results indicate that the kneechest, compared with the supine position, does not produce any modification of CBF in healthy patients undergoing intervertebral lumbar disc surgery. However, further studies are required to determine the influence of this position on cerebral perfusion in patients with cerebrovascular diseases.

This work was supported in part by a grant of the Swiss National Fund for Scientific Research No 3.822-0.83.

\section{References}

1 Lipton S. Anesthesia in the surgery of retropulsed vertebral discs. Anaesthesia 1950;5:208-12.

2 Taylor AR, Gleadhill CA, Bilsland WL. Posture and anaesthesia for spinal operations with special reference to intervertebral disc surgery. Br $J$ Anaesth 1956;28: 213-9.

3 Pearce DJ. The role of posture in laminectomy. Proc $R$ Soc Med 1957;50:109-12.

4 Wayne SJ. The tuck position for lumbar disc surgery. $J$ Bone Joint Surg 1967;49:1195-8.

5 Laurin CA, Migneault G, Brunet JL. Knee-chest support for lumbosacral operations. Can J Surg 1969;12: 245-50.
6 Alexander JP. Problems associated with the use of the knee-chest position for operations on lumbar intervertebral discs. J Bone Joint Surg 1973;55:279-84.

7 Gordon BS, Newman W. Lower nephron syndrome following prolonged knee-chest position. J Bone Joint Surg 1953;35:764-8.

8 Toole JF. Effects of change of head, limb and body position on cephalic circulation. $N$ Engl J Med 1968; 279:307-11.

9 Risberg J, Ali Z, Wilson EH. Regional cerebral blood flow by ${ }^{133}$ xenon inhalation. Stroke 1975;6:142-8.

10 Obrist WD, Thompson HK, Wang HS. Regional cerebral blood flow estimated by xenon-133 inhalation. Stroke 1975;6:245-56.

11 Eger EI, Saidman LJ, Brandstater B. Minimum alveolar anesthetic concentration. A standard of anesthetic potency. Anesthesiology 1965;26:765-73.

12 Drummond JC, Todd MM, Toutant SM. Brain protrusion during enflurane, halothane and isoflurane anesthesia in the cats. Anesthesiology 1983;59:288-93.

13 McPherson RW, Traystman RJ. Effects of isoflurane on cerebral autoregulation. Anesthesiology 1987;67:A576.

14 King BD, Harris LC, Greifenstein FE. Reflex circulatory responses to direct laryngoscopy and tracheal intubation performed during general anesthesia. Anesthesiology 1951;12:556-66.

15 O'Connell JEA. Vascular factor in intracranial pressure and in maintenance of cerebrospinal fluid circulation. Brain 1943;66:204-28.

16 Nelson RJ, Lovick AHJ, Pickard JD, Brice J, Saunders D, Horsey PJ. Changes in cerebral blood flow during anaesthesia and surgery in the sitting position. $J$ Neurol Neurosurg Psychiatry 1987;50:971-5. 